\title{
Translation and Validation of the Japanese Version of the Family Sense of Coherence Scale-Short Form in Nurses
}

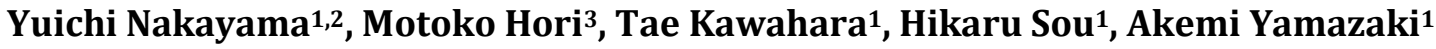 \\ ${ }^{1}$ Division of Health Sciences, Osaka University Graduate School of Medicine, Osaka, Japan \\ ${ }^{2}$ Faculty of Nursing, Setsunan University, Osaka, Japan \\ ${ }^{3}$ Faculty of Nursing, SenriKinran University, Osaka, Japan \\ Email: akemiyamazaki@sahs.med.osaka-u.ac.jp
}

How to cite this paper: Nakayama, Y., Hori, M., Kawahara, T., Sou, H. and Yamazaki, A. (2019) Translation and Validation of the Japanese Version of the Family Sense of Coherence Scale-Short Form in Nurses. Open Journal of Nursing, 9, 901-910. https://doi.org/10.4236/ojn.2019.98067

Received: June 20, 2019

Accepted: August 23, 2019

Published: August 26, 2019

Copyright (c) 2019 by author(s) and Scientific Research Publishing Inc. This work is licensed under the Creative Commons Attribution International License (CC BY 4.0).

http://creativecommons.org/licenses/by/4.0/

\begin{abstract}
Purpose: The purpose of this study was to translate the Family Sense of Coherence Scale-short form (FSOC-S) into a Japanese version (J-FSOC-S) for Japanese nurses and to evaluate its reliability and validity. Methods: First, we obtained permission to translate the FSOC-S from the original author and translated it into Japanese using the translation/back translation technique. Second, the J-FSOC-S was reviewed by a panel of experts in nursing research and practice, then, a validation survey was conducted. The internal consistency of the J-FSOC-S was assessed using Cronbach's $\alpha$ coefficient. Test-retest reliability was examined through intra-class correlation coefficients (ICC). Construct validity was investigated by measuring the correlation coefficients between the J-FSOC-S and Sense of Coherence (SOC) Scale (concurrent validity) and the Family Adaptability Partnership, Growth, Affection, and Resolve Index (Family APGAR) (convergent validity). Results: A total of 374 nurses (valid response rate $=58.6 \%$ ) were recruited from seven hospitals. Thirty-four participants completed the questionnaire twice at an interval of 2 - 4 weeks to test the reliability. The mean age of the participants was 35.0 years $(\mathrm{SD}=7.6$, range $=25-59)$. The mean years of experience as a registered nurse were 11.0 years $(\mathrm{SD}=7.1$, range $=5-36)$. Of the total number of participants, $53.7 \%$ had children. The J-FSOC-S showed good internal consistency (Cronbach's $\alpha=0.85$ ) and test-retest reliability (ICC $=0.77$ ). The J-FSOC-S correlated positively with the SOC Scale $(\mathrm{r}=0.41, \mathrm{p}<0.01)$ and the Family APGAR $(r=0.62, p<0.01)$. Conclusions: The J-FSOC-S is a reliable and valid instrument for measuring family sense of coherence in Japan.
\end{abstract}

\section{Keywords}

Family Sense of Coherence, Psychometric Testing, Nurses 


\section{Introduction}

Sense of coherence (SOC) reflects a person's ability to cope with stressful situations in life. SOC is defined as the perception that various events and immediate environments that arise in a person's life are coherent, and is composed of the subordinate concepts of meaningfulness, manageability, and comprehensibility [1]. The international scale for SOC has been translated into over 30 languages and is widely used [2]. The concept of SOC applies not just to people, but also to social units in the form of groups, such as cities, nations, organizations, and even families [1]; however, research on the SOC of groups is still in development [3]. Family Sense of Coherence (FSOC) is an adaptation of Antonovsky's concept of SOC to families. FSOC reflects the ability of families to cope with stress that they face as a group, and the FSOC Scale is used, for example, as a metric in interventional studies of protective factors against childhood obesity for low-income preschool children [4] and of families with a critically ill family member [5], and is also used as a buffering factor for internalized stigma and health-related quality of life (QOL) in schizophrenia [6]. The original FSOC Scale is comprised of 26 items, and a short version with 12 items (FSOC-S) rated on a 7-point scale has also been developed [7]. The total score in the short version ranges from 12 to 84 and a higher score reflects better perceptions of the coherence of family. The FSOC has been translated into Chinese [8], Turkish [9], and Norwegian [10] and its validity has been confirmed.

Nurses' ability to cope with stress is a factor that influences their QOL and has been reported in many studies internationally [11]-[15]. SOC has also been reported to be a predictor of nurses' QOL [16]. Furthermore, mid-career nurses often take on many roles within their family, such as caring for children, making work-family conflict (WFC) an issue. Especially in Asia, strong value is placed on family roles. In an international comparative study of the QOL of nurses in Japan, Singapore, and Malaysia, SOC was, as with social support, a predictor of nurses' QOL [17]. WFC has an impact on the mental and physical health of Japanese nurses and SOC is a buffering factor for WFC-related stress [18]. Accordingly, the development of a Japanese language version of a scale that can easily measure the SOC of families might contribute to the development of this field of research. The purpose of this study was to translate the FSOC-S [7] into a Japanese version (J-FSOC-S) for Japanese nurses and to evaluate its reliability and validity.

\section{Methods}

\subsection{Translation and Back-Translation of the Family Sense of Coherence Scale}

We obtained permission to translate the FSOC-S from the original author, Dr. ShifraSagy. After that, we translated the FSOC-S from English into Japanese and then used the back-translation technique to translate it back into English [19]. The cultural equivalence of the J-FSOC-S was verified by an expert panel com- 
posed of an academic researcher in family nursing who received a Ph.D. in the United States, a translator specializing in medicine, and five academics with nursing experience in Japan. The Japanese version was back-translated into English by a translation specialist who never saw the original English version. We compared the back-translated version to the original version and Dr. Sagy also checked the back-translated version and requested revision to one item. We then conducted a pilot test on a convenience sample of 20 licensed nurses. These 20 nurses found some of the questions or response choices difficult to understand (items 1, 2, 5, 9, 10). Therefore, we altered these items to more closely match the original English version. Dr. Sagy approved the final version of the J-FSOC-S.

\subsection{Validation Survey}

We conducted a cross-sectional study in regional hospitals in Japan using a selfadministered questionnaire to evaluate the reliability and validity of the J-FSOC-S. The reliability of the J-FSOC-S was assessed for internal consistency and test-retest reliability. A 2- to 4-week interval was used for test-retest reliability to assess the stability of the scale. Construct validity was examined by testing the correlation between the J-FSOC-S and conceptually related measures, including the SOC Scale [20], and the Family Adaptability Partnership, Growth, Affection, and Resolve Index (Family APGAR) [21]. Positive correlations were expected between J-FSOC-S scores and scores of the SOC Scale and the Family APGAR. Nurses who experienced a strong sense of difficulty with their role of caring for children in their family were also subject to an examination of known-groups validity based on the hypothesis that the family's FSOC was low.

\subsection{Participants}

We recruited nurses from seven medical facilities in Japan between January and February 2018. The inclusion criterion was nurses with more than 5 years of clinical experience. The exclusion criteria were nurses in a managerial position, foreign nationals, and nurses on maternity leave, childcare leave or nursing care leave. We asked representatives of the seven facilities to select participants who met the inclusion criteria, and to distribute and collect the questionnaires.

\subsection{Ethical Considerations}

This study was approved by the Institutional Review Board of Osaka University (No. 17269). All participants were informed in writing about the purpose of the study, that all responses were anonymous, that individual participants could not be identified, that they could drop out at any time without penalty, and that there was no disadvantage to choosing not to participate or leaving blank answers in the questionnaire.

\subsection{Measures}

The questionnaire contained items on the participants' demographic characte- 
ristics, as well as the J-FSOC-S, SOC Scale, and the Family APGAR. Demographic characteristics of the participants consisted of sex, age, the number of years of clinical experience, experience as an administrator, family nursing experience, the number of years of family nursing, presence of a partner, presence of children, difficulty with childcare, experience caring for a family member and educational background.

\subsubsection{Japanese Version of the Family Sense of Coherence Scale}

The FSOC-S is a short version of the 26-item FSOC [22] and was designed to assess the degree to which the family views their environment as comprehensible, manageable, and meaningful [7]. It consists of 12 semantically different items rated on a 7-point scale. Total scores range from 12 to 84, with higher scores indicating a family's stronger perception of the coherence of family life.

\subsubsection{Sense of Coherence Scale}

The SOC Scale consists of 29 items designed to assess an individual's global view that their environment is comprehensible, manageable, and meaningful [20]. A 13-item version of the SOC has been developed and translated into several languages, with good internal consistency, test-retest reliability, and construct and criterion validity [2] [20]. Each item is scored on a 7-point semantic differential with two anchoring phrases. Total scores range from 13 to 91, with higher scores reflecting a stronger SOC. The Japanese version of the 13-item SOC has shown satisfactory reliability (Cronbach's $\alpha=0.81$ ) and validity [23].

\subsubsection{Family APGAR}

The Family APGAR was developed by Smilkstein in 1978 [24]. It is a reliable, validated, utilitarian instrument to measure a subject's satisfaction with five components of family function: adaptation, partnership, growth, affection, and resolve. Higher scores indicate higher family functioning. Reliability and validity of this instrument have been reported previously [25]. The Japanese version of the Family APGAR was used in this study [21].

\subsubsection{Data Analysis}

Descriptive statistics for all variables were calculated by using SPSS ver.24 for Windows. The internal consistency of the J-FSOC-S was assessed by Cronbach's $\alpha$ coefficient. The test-retest reliability between the initial questionnaire and follow-up questionnaire 2 to 4 weeks later was calculated using the intra-class correlation coefficient (ICC). The construct validity of the scale was examined by calculating Spearman's rank correlation coefficient between the J-FSOC-S and the SOC Scale (concurrent validity) and the Family APGAR (convergent validity). Results were considered to be statistically significant where $\mathrm{p}<0.05$.

\section{Findings}

\subsection{Participant Characteristics}

Questionnaires were distributed to 638 nurses from seven medical facilities and 
480 nurses responded (response rate $=75.2 \%$ ). The seven medical facilities were located in cities ranging in population size from 2.7 million people to provincial cities of 35,000 people. One facility was an advanced treatment hospital. The mean number of beds was 585 (range: 199 - 1063). The nurses' affiliated departments are as shown in Table 1 . The majority of "Other" departments were mixed wards. Valid responses were received from 374 nurses (valid response rate $=58.6 \%)$. Only 100 nurses from one facility were asked to participate in the test-retest and 34 participants completed the test-retest reliability study. The characteristics of participants are shown in Table 1 . The mean age of the participants was 35.0 years ( $\mathrm{SD}=7.6$, range $=25$ - 59 years). The majority of the participants (93.0\%) were female. The mean length of clinical experience was 11.0 years $(\mathrm{SD}=7.1$, range $=5$ - 36 years). In addition, $53.7 \%$ were nurses currently providing child care, approximately $80 \%$ of whom experienced child care-related difficulties.

\subsection{Score Distribution and Acceptability}

The average scores \pm SD of the J-FSOC-S items are shown in Table 2. The J-FSOC-S showed signs of a ceiling effect in items 1 and 8. Homogeneity was explored by corrected item-total correlations. Item-total correlations of the 12 items ranged between $0.41-0.71$, which indicated satisfactory homogeneity of the items. Figure 1 shows a histogram of total score distribution of the J-FSOC-S.

\subsection{Reliability and Validity}

Cronbach's $\alpha$ coefficient of the J-FSOC-S was 0.85 , indicating adequate internal consistency. The intra-class correlation coefficient was 0.77 , indicating satisfactory stability of the J-FSOC-S over a 2- to 4-week period (Table 3).

The mean score of the J-FSOC-S was $58.0(\mathrm{SD}=11.2)$. The J-FSOC-S scores correlated positively with the SOC Scale $(r=0.41, \mathrm{p}<0.01)$ and the Family APGAR $(r=0.62, \mathrm{p}<0.01)$ (Table 3$)$. These results indicate the construct validity of the J-FSOC-S.

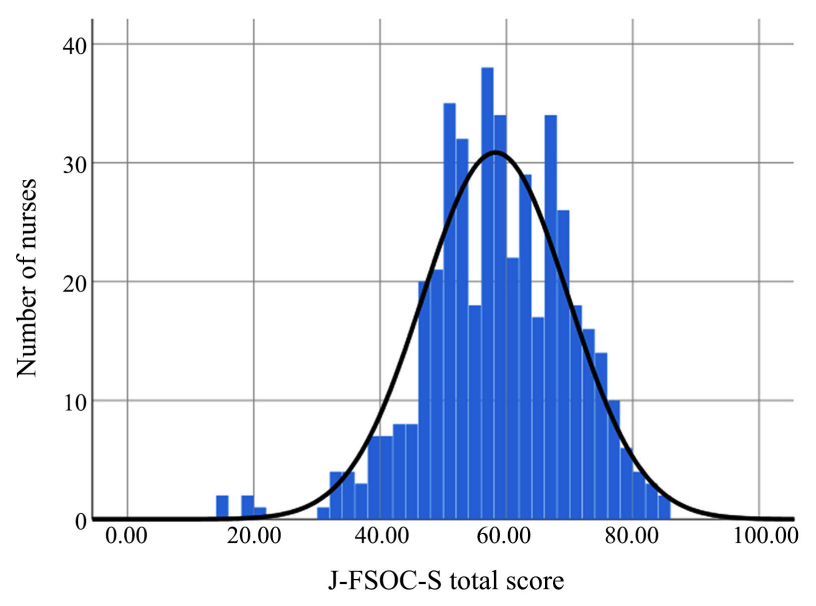

Figure 1. Total score distribution of the J-FSOC-S. 
Table 1. Participant characteristics $(\mathrm{N}=374)$.

\begin{tabular}{|c|c|}
\hline & $\mathrm{n}, \%$ or mean $\pm \mathrm{SD}$ (range) \\
\hline Mean age \pm SD (years) & $35.0 \pm 7.6(25-59)$ \\
\hline \multicolumn{2}{|l|}{ Sex } \\
\hline Male & $26(7.0 \%)$ \\
\hline Female & $348(93.0 \%)$ \\
\hline Mean clinical experience (years) & $11.0 \pm 7.1(5-36)$ \\
\hline \multicolumn{2}{|l|}{ Experience as a nurse manager } \\
\hline Yes & $54(14.4 \%)$ \\
\hline No & $320(86.5 \%)$ \\
\hline \multicolumn{2}{|l|}{ Presence of a partner } \\
\hline Yes & $206(55.1 \%)$ \\
\hline No & $168(44.9 \%)$ \\
\hline \multicolumn{2}{|l|}{ Presence of children } \\
\hline Yes & $201(53.7 \%)$ \\
\hline No & $173(46.3 \%)$ \\
\hline \multicolumn{2}{|l|}{ Difficulty with childcare } \\
\hline Very difficult & $51(25.4 \%)$ \\
\hline Difficult & $111(55.2 \%)$ \\
\hline Not difficult & $32(15.9 \%)$ \\
\hline None & $7(3.5 \%)$ \\
\hline \multicolumn{2}{|l|}{ Educational background } \\
\hline 2-year diploma program & $36(9.6 \%)$ \\
\hline 3-year diploma program & $207(72.7 \%)$ \\
\hline Junior college & $19(5.1 \%)$ \\
\hline University & $83(22.2 \%)$ \\
\hline Graduate school & $5(1.3 \%)$ \\
\hline Other & $24(6.4 \%)$ \\
\hline \multicolumn{2}{|l|}{ Affiliated department } \\
\hline Outpatient department & $31(8.3 \%)$ \\
\hline Obstetrics department & $26(7.0 \%)$ \\
\hline Emergency department & $23(6.1 \%)$ \\
\hline Gastrointestinal department & $20(5.3 \%)$ \\
\hline Intensive care unit & $18(4.8 \%)$ \\
\hline Neonatal intensive care unit & $18(4.8 \%)$ \\
\hline Surgery department & $18(4.8 \%)$ \\
\hline Orthopedic surgery department & $17(4.5 \%)$ \\
\hline Operating room & $16(4.3 \%)$ \\
\hline Cardiovascular department & $14(3.7 \%)$ \\
\hline Internal medicine department & $14(3.7 \%)$ \\
\hline Neurosurgery department & $14(3.4 \%)$ \\
\hline Respiratory department & $13(3.5 \%)$ \\
\hline High care unit & $10(2.7 \%)$ \\
\hline Pediatric department & $10(2.7 \%)$ \\
\hline Other & $112(29.9 \%)$ \\
\hline
\end{tabular}

SD: standard deviation. 
Table 2. J-FSOC-S items and scores.

\begin{tabular}{|c|c|c|c|}
\hline $\begin{array}{l}\text { Item } \\
\text { No. }\end{array}$ & & $\begin{array}{l}\text { J-FSOC-S score } \\
(\text { mean } \pm \text { SD })\end{array}$ & $\begin{array}{c}\mathrm{I}-\mathrm{T} \\
\text { Correlation }\end{array}$ \\
\hline 1 & $\begin{array}{l}\text { To what extent do you think that you have influence on } \\
\text { what happens to your family? }\end{array}$ & $5.73 \pm 1.43$ & $0.53^{* *}$ \\
\hline 2 & $\begin{array}{l}\text { When you need to do things that require collaboration } \\
\text { from all family members, your feeling is ...? }\end{array}$ & $5.54 \pm 1.24$ & $0.67^{* *}$ \\
\hline 3 & Up to now, your family life has been ...? & $4.67 \pm 1.60$ & $0.67^{* *}$ \\
\hline 4 & $\begin{array}{l}\text { To what extent do you think that your family's rules and } \\
\text { norms are clear? }\end{array}$ & $3.91 \pm 1.57$ & $0.41^{* *}$ \\
\hline 5 & When your family has a big problem, your feeling is ...? & $4.11 \pm 1.40$ & $0.48^{* *}$ \\
\hline 6 & Your family life is ...? & $4.18 \pm 1.56$ & $0.70^{* *}$ \\
\hline 7 & $\begin{array}{l}\text { To what extent do you see a clear future for your family } \\
\text { and how do you expect to see your family in } 3 \text { years? }\end{array}$ & $4.03 \pm 1.65$ & $0.62^{* *}$ \\
\hline 8 & Do you feel that your family treats you fairly? & $5.93 \pm 1.40$ & $0.57^{* *}$ \\
\hline 9 & When you think about your family, your feeling is ...? & $5.55 \pm 1.34$ & $0.71^{* *}$ \\
\hline 10 & $\begin{array}{l}\text { The activities you do as part of your family } \\
\text { responsibilities cause you ...? }\end{array}$ & $5.39 \pm 1.36$ & $0.70^{* *}$ \\
\hline 11 & $\begin{array}{l}\text { Do you sometimes feel that you don't have a clear idea of } \\
\text { what is going to happen in your family? }\end{array}$ & $4.28 \pm 1.73$ & $0.64^{* *}$ \\
\hline 12 & Has a family member you trusted ever disappointed you? & $4.91 \pm 1.70$ & $0.59^{* *}$ \\
\hline
\end{tabular}

SD: standard deviation; I-T Correlation: item-total correlation. ${ }^{* *} \mathrm{p}<0.01$.

Table 3. Internal consistency, test-retest correlation, and correlations of the J-FSOC-S with the SOC Scale and Family APGAR Index.

\begin{tabular}{ccccc}
\hline J-FSOC-S & Cronbach's $\alpha$ & ICC & SOC Scale & Family APGAR Index \\
\hline Total sample $(\mathrm{N}=374)$ & 0.85 & $0.77^{* *}$ & $0.41^{* *}$ & $0.62^{* *}$ \\
\hline
\end{tabular}

J-FSOC-S: Japanese version of the Family Sense of Coherence Scale-Short Form; SOC Scale: Sense of Coherence Scale, Family APGAR Index: Family Adaptability Partnership, Growth, Affection, and Resolve Index; ICC: intra-class correlation coefficient. ${ }^{* *} \mathrm{p}<0.01$.

Of the 374 nurses, the 201 nurses currently providing child care were subject to an examination of known-groups validity. A one-way analysis of variance was used to compare the nurses organized into three groups based on their level of child care-related difficulty (very difficult, difficult, and not difficult + none). The results showed significant differences in the J-FSOC-S score $(\mathrm{F}(2199)=$ 8.035, $\mathrm{p}<0.01)$. A multiple comparison test revealed that nurses who responded with "very difficult" or "difficult" in relation to child care-related difficulty had significantly lower J-FSOC-S scores than nurses who had no difficulty. This validated the hypothesis that a low J-FSOC-S score is associated with a poorer ability of families to cope with child care-related stress as a group and a greater sense of child care-related difficulty.

\section{Discussion}

We translated the FSOC-S into Japanese, and analyzed its validity and reliability. Cronbach's $\alpha$ coefficient was calculated as a measure of internal consistency, and 
a value between 0.7 and 0.9 is generally considered to indicate good internal consistency. The results of the present study indicate a high level of similarity among the items. The stability of the J-FSOC-S analyzed with test-retest was found to be good. The ICC in the present study 0.77 was similar with Ngai's study of the Chinese version 0.75 [8] and with Moen's study of the Norwegian version 0.85 [10] and Cecen's study of the Turkish version 0.85 [9].

The J-FSOC-S was positively correlated with the SOC Scale, demonstrating that the J-FSOC-S contained concurrent validity. This result is congruent with previous studies that found a significant association between family and individual SOC [7] [10] [26]. The J-FSOC-S was also positively correlated with the Family APGAR. Previous studies measured the correlation between the FSOC and various family functioning measures, such as the Medical Outcome Study Family and Marital Functioning Measures [8] and Family Assessment Device [9] [10], to investigate the convergent validity. These previous studies indicate similar findings to the present study, indicating that the J-FSOC-S is a valid tool to evaluate family function.

The results of this study support the reliability and validity of the J-FSOC-S. This scale can be used to evaluate family SOC in Japanese nurses. The mean age of the participants was 35.0 years ( $\mathrm{SD}=7.6$, range $=25-59$ ). This was similar to the age of the participants in Ngai's study [8], in which an FSOC scale was developed for Chinese childbearing couples. The participants of the present study were nurses, half of whom were providing child care. Considering that a person's SOC develops until they are in their 30s [1], FSOC may also be expected to develop as families overcome the challenges associated with child care. The J-FSOC-S developed in the present study could be used in research that will contribute to the mental and physical health of Japanese nurses.

\section{Conclusion}

We developed a Japanese version of the FSOC Scale, which we trialed in 374 Japanese nurses. This study had one limitation. A ceiling effect was seen in item 1, "To what extent do you think that you have influence on what happens to your family?" and in item 8 , "Do you feel that your family treats you unfairly?" which correspond to the subordinate concept of "sense of manageability" of the FSOC. Moreover, because half of the Japanese nurses working as mid-career nurses in this study were in the process of providing child care, these nurses had an influential presence in their family, thus causing bias in the distribution. Despite the aforementioned limitation, the study results demonstrated the reliability and validity of the J-FSOC-S. This scale can, therefore, be used to evaluate family SOC in Japanese nurses.

\section{Acknowledgements}

The authors would like to sincerely thank the nurses at the seven participating hospitals for their kind cooperation with this research. This work was presented 
at the 14th Asia Pacific Sociological Conference in October, 2018 in Hakone, Japan. Y.N. and M.H. contribute equally to this work. This study was supported by JSPS KAKENHI Grant Number 16H05565 (PI: A. Yamazaki).

\section{Conflicts of Interest}

The authors declare no conflicts of interest regarding the publication of this paper.

\section{References}

[1] Antonovsky, A. (1987) Unraveling the Mystery of Health: How People Manage Stress and Stay Well. Jossey-Bass Publishers, San Francisco.

[2] Eriksson, M. and Lindstrom, B. (2005) Validity of Antonovsky's Sense of Coherence Scale: A Systematic Review. Journal of Epidemiology and Community Health, 59, 460-466. https://doi.org/10.1136/jech.2003.018085

[3] Yamazaki, Y., Togari, T. and Sakano, J. (2019) Stress Coping: Sense of Coherence. Yushindo, Tokyo.

[4] Speirs, K.E., Hayes, J.T., Musaad, S., VanBrackle, A., Sigman-Grant, M. and the All 4 Kids Obesity Resiliency Research Team (2016) Is Family Sense of Coherence a Protective Factor against the Obesogenic Environment? Appetite, 99, 268-276. https://doi.org/10.1016/j.appet.2016.01.025

[5] Agren, S., Eriksson, A., Fredrikson, M., Hollman-Frisman, G. and Orwelius, L. (2019) The Health Promoting Conversations Intervention for Families with a Critically Ill Relative: A Pilot Study. Intensive \& Critical Care Nursing, 50, 103-110. https://doi.org/10.1016/j.iccn.2018.04.007

[6] Hsiao, C.Y., Lu, H.L. and Tsai, Y.F. (2018) Effect of Family Sense of Coherence on Internalized Stigma and Health-Related Quality of Life Among Individuals with Schizophrenia. International Journal of Mental Health Nursing, 27, 138-146. https://doi.org/10.1111/inm.12302

[7] Sagy, S. (1998) Effects of Personal, Family, and Community Characteristics on Emotional Reactions in a Stress Situation: The Golan Heights Negotiations. Youth \& Society, 29, 311-329. https://doi.org/10.1177/0044118X98029003003

[8] Ngai, F.W. and Ngu, S.F. (2011) Translation and Validation of a Chinese Version of the Family Sense of Coherence Scale in Chinese Childbearing Families. Nursing Research, 60, 295-301. https://doi.org/10.1097/NNR.0b013e3182269b00

[9] Cecen, A.R. (2007) The Turkish Version of the Family Sense of Coherence Scale-Short Form (FSOC-S): Initial Development and Validation. Kuram Ve Uygulamada Egitim Bilimleri, 7, 1199-1220. https://doi.org/10.1037/t68569-000

[10] Moen, Ø.L. and Hall-Lord, M.L. (2016) Reliability and Validity of the Norwegian Family Sense of Coherence Scale. Open Journal of Nursing, 6, 1075-1086. https://doi.org/10.4236/ojn.2016.612102

[11] Augusto Landa, J.M., Lopez-Zafra, E., Berrios Martos, M.P. and Aguilar-Luzon, M.C. (2008) The Relationship between Emotional Intelligence, Occupational Stress and Health in Nurses: A Questionnaire Survey. International Journal of Nursing Study, 45, 888-901. https://doi.org/10.1016/j.ijnurstu.2007.03.005

[12] Chang, E.M., Bidewell, J.W., Huntington, A.D., Daly, J., Johnson, A., Wilson, H., et al. (2007) A Survey of Role Stress, Coping and Health in Australian and New Zealand Hospital Nurses. International Journal of Nursing Study, 44, 1354-1362. https://doi.org/10.1016/j.ijnurstu.2006.06.003 
[13] Lambert, V.A., Lambert, C.E., Itano, J., Inouye, J., Kim, S., Kuniviktikul, W., et al. (2004) Cross-Cultural Comparison of Workplace Stressors, Ways of Coping and Demographic Characteristics as Predictors of Physical and Mental Health among Hospital Nurses in Japan, Thailand, South Korea and the USA (Hawaii). International Journal of Nursing Study, 41, 671-684. https://doi.org/10.1016/j.ijnurstu.2004.02.003

[14] Lambert, V.A., Lambert, C.E., Petrini, M., Li, X.M. and Zhang, Y.J. (2007) Workplace and Personal Factors Associated with Physical and Mental Health in Hospital Nurses in China. Nursing Health Sciences, 9, 120-126. https://doi.org/10.1111/j.1442-2018.2007.00316.x

[15] Wu, S.Y., Li, H.Y., Tian, J., Zhu, W., Li, J. and Wang, X.R. (2011) Health-Related Quality of Life and Its Main Related Factors among Nurses in China. Industrial Health, 49, 158-165. https://doi.org/10.2486/indhealth.MS1160

[16] Malinauskiene, V., Leisyte, P., Romualdas, M. and Kirtiklyte, K. (2011) Associations between Self-Rated Health and Psychosocial Conditions, Lifestyle Factors and Health Resources among Hospital Nurses in Lithuania. Journal of Advance Nursing, 67, 2383-2393. https://doi.org/10.1111/j.1365-2648.2011.05685.x

[17] Kowitlawkul, Y., Yap, S.F., Makabe, S., Chan, S., Takagai, J., Tam, W.W.S., et al. (2019) Investigating Nurses' Quality of Life and Work-Life Balance Statuses in Singapore. International Nursing Review, 66, 61-69. https://doi.org/10.1111/inr.12457

[18] Takeuchi, T. and Yamazaki, Y. (2010) Relationship between Work-Family Conflict and a Sense of Coherence among Japanese Registered Nurses. Japan Journal of Nursing Sciences, 7, 158-168. https://doi.org/10.1111/j.1742-7924.2010.00154.x

[19] Polit, D.F. and Beck, C.T. (2012) Nursing Research: Generating and Assessing Evidence for Nursing Practice. Wolters Kluwer Health, Philadelphia.

[20] Antonovsky, A. (1993) The Structure and Properties of the Sense of Coherence Scale. Social Sciences Medicine, 36, 725-733. https://doi.org/10.1016/0277-9536(93)90033-Z

[21] Kamibeppu, K. (2011) Establishment of Family Nursing Skills and Liaison Systems between Hospitals and Other Social Resources to Realize Child Abuse Prevention from the Perinatal Period. Grant-in-Aid for Scientific Research Paper (B) No. 21390589.

[22] Antonovsky, A. and Sourani, T. (1988) Family Sense of Coherence and Family Adaptation. Journal of Marriage and the Family, 50, 79-92. https://doi.org/10.2307/352429

[23] Togari, T. and Yamazaki, Y. (2005) Examination of the Reliability and Factor Validity of 13-Item Five-Point Version Sense of Coherence Scale. Japanese Journal of Health Human Ecology, 71, 168-182. https://doi.org/10.3861/jshhe.71.168

[24] Smilkstein, G. (1978) The Family APGAR: A Proposal for a Family Function Test and Its Use by Physicians. Journal of Family Practice, 6, 1231-1239.

[25] Smilkstein, G., Ashworth, C. and Montano, D. (1982) Validity and Reliability of the Family APGAR as a Test of Family Function. Journal of Family Practice, 15, 303-311.

[26] Sagy, S. and Braun-Lewensohn, O. (2009) Adolescents under Rocket Fire: When Are Coping Resources Significant in Reducing Emotional Distress? Global Health Promotion, 16, 5-15. https://doi.org/10.1177/1757975909348125 